\title{
The examined life: perspectives of lower primary school students in Hong Kong
}

David Carless, University of Hong Kong \& Ricky Lam, Hong Kong Institute of Education

Accepted to appear in the journal: Education 3-13

\begin{abstract}
Students have a wide experience of being tested, but their perceptions of assessment are comparatively under-explored. This paper illuminates the perspectives on assessment of a sample of lower primary school students in Hong Kong. It uses focus group interviews and draw-a-picture technique to elicit their views. The main findings are that assessment can bring a sense of satisfaction or happiness, but that more than half of the informants indicated that they had negative feelings in relation to testing. The paper reinforces how students are controlled and moulded by their assessment experience, and its significance lies principally in documenting this phenomenon amongst lower primary school learners.
\end{abstract}

Keywords: student perceptions; assessment; the power of tests

\section{Introduction}

The American anthropologist Allan Hanson (1993) has written of the social consequences of the 'examined life' and argued that individuals are defined and dominated by tests. Whilst these repercussions of assessment are commonly observed, for example, amongst senior secondary students, the response of lower primary school students to assessment is comparatively under-explored. How this age group reacts to testing is particularly important because if early experiences of assessment or schooling are negative, this can impede young learners from developing the capacities and dispositions required for a successful school career.

Assessment can afford students a sense of success in that high levels of achievement often lead to positive self-esteem (Black, 1998). Students also sometimes associate assessment with pleasure of being praised or fear of receiving punishments from teachers or parents (Pollard \& Triggs, 2000). Students often label themselves as 
'winners' or 'losers' on the basis of test results and a repercussion is that lower achieving students may become discouraged from engaging fully in schooling (Harlen \& Deakin-Crick, 2003; Harlen, 2006).

Students in Confucian-influenced societies, such as Hong Kong, Japan, Singapore, South Korea and Taiwan generally perform well on international tests of achievement, such as TIMSS or PIRLS and this has attracted the interest of policy-makers in other countries. Despite these apparent high levels of achievement, students in Hong Kong seem to carry perceptions of low self-efficacy (House, 2003; Shen \& Tam, 2008). This potential disjunction between high achievement and a low sense of self-worth makes the perspectives of Hong Kong students particularly worth exploring.

The aim of this exploratory paper is to identify the perspectives on assessment of a sample of lower primary school students in Hong Kong. The main significance of the paper lies in documenting and analyzing the powerful impact of testing on primary school students. Although some aspects of this issue have been discussed in relation to Chinese societies over the last twenty years (e.g. Biggs, 1996; Zeng, 1999), the research base from the student perspective is modest, particularly in the early years of primary schooling. In view of trends internationally for more accountability and more testing (Black \& Wiliam, 2005), we believe these issues are highly relevant to the international educational community.

\section{Conceptual framework: the power of tests}

The framework for the paper is developed in two stages. First, we use conceptual work of sociologists, such as Foucault and Bourdieu which reveals the role of assessment as a means of competition, selection and social control, and the power of examinations to mould the individual to societal and institutional norms. Second, we use empirical research in relation to student responses to assessment to elaborate how students perceive assessment as impacting on themselves and their school experience.

Foucault (1979) analyses the role of assessment as a source of power and as a disciplinary tool setting norms which classify individuals and hold them under surveillance. According to Foucault (1979, p.184) the examination is "a surveillance that makes it possible to qualify, to classify and to punish. It establishes over 
individuals a visibility through which one differentiates them and judges them”. For Foucault, the school becomes an apparatus of uninterrupted examination which perpetually compares students to each other, measures and judges them. The pervasiveness of the examination in the school system makes it "a constantly repeated ritual of power” (Foucault, 1979, p. 186).

For Bourdieu (1991) tests are instruments of symbolic power which create a perception of test results as being a major criterion of individual worth. The presentation of the examination as a 'moment of truth' with its own objective reality masks the links between the school system and the structure of class relations (Bourdieu \& Passeron, 1990). The competitive element of assessment is illustrated by the fine line between success and failure in examinations: "between the last person to pass and the first person to fail, the competitive examination creates differences of all or nothing that can last a lifetime” (Bourdieu, 1991, p. 120).

According to Hanson (1993), the two most important consequences of tests are that they are mechanisms for defining or producing the concept of the person and that they maintain the person under surveillance and domination. Tests exert power which prompts students and teachers to adjust their behaviors to fall in line with the testing apparatus. As Hanson (1993, p. 294) puts it, "tests create that which they purport to measure by transforming the person”. For students, learning can then become less a matter of acquiring knowledge than becoming adept at cramming and other testtaking techniques, for example, recognizing random facts for multiple choice tests rather than constructing patterns of logical thought (Hanson, 1993).

The Israeli applied linguist, Elana Shohamy (2001) also discusses the power of tests and their appeal to many parents who see them as a sign of discipline or quality education. For parents who often do not trust schools and teachers, tests provide a symbol of control and means of perpetuating dominance of elite groups (Shohamy, 2001). Tests use numbers which are symbols of objectivity and rationality enabling quantification, classification and the standardization of students according to a common yardstick (Shohamy, 1998). 
Turning now to the second part of our framework, we review selected empirical research which draws out students' perspectives on assessment. In a 5-year crosssectional study of successive cohorts of year 2 and year 6 students under the English National Curriculum, Davies and Brember (1998) found that the self-esteem of year 2 learners declined each year, and the largest decline was at that time of the introduction of National Curriculum testing. A related inference was that test scores in the National Curriculum matter to the parent, the teacher and the school and every child is aware of this (Davies \& Brember, 1998). Reay and Wiliam (1999) show the powerful impact of standardized tests on children's lives. Drawing on classroom observations, individual and focus group interviews with year 6 students, they develop a picture of strong currents of fear and anxiety related to testing, with students expressing a perception that a test can make a single definitive statement about the sort of person they are (Reay \& Wiliam, 1999). Based on ethnographic data from two English primary schools, Hall et al., (2004) depict a similar story of students being constructed by testing, fearing failure and being afraid of disappointing their parents. Testing regimes, according to Hall et al., (2004), lead to the construction of an image of 'ideal' parents who check that homework is done, understand external high-stakes tests and share a school's emphasis on achievement as defined by tests.

A study of a large opportunistic sample of year 4, 8 and 10 students in Massachusetts involved teachers submitting students' drawings of themselves taking the state highstakes test (Wheelock et al., 2000). It was found that whilst a minority of students drew pictures which indicated positive images of themselves as diligent thinkers or problem-solvers, the majority depicted images of anxiety, boredom or pessimism. High school students in Queensland revealed that they were mainly positive about their assessment experiences in primary schools but over the course of secondary schooling, they became increasingly negative about the nature of assessment and concerned about its impact on their lives (Moni, Van Kraayenoord \& Baker, 2002).

To sum up, testing exerts power over students' behaviours and experiences, and how they are perceived or classified as individuals. It can lead to feelings of satisfaction or achievement, but can also prompt anxiety or generate threats to self-esteem. Few studies have focused on lower primary school students and this is one of the motivations for the current study. 


\section{The contextual background}

Assessment is a socio-culturally influenced phenomenon which impacts on how students perceive and experience assessment (Gipps, 1999). Accordingly, we wish to contextualize the paper (as far as space limitations permit) via a brief introduction to selected aspects of the Hong Kong education system.

A relevant socio-cultural dimension is the historical role of competitive examinations in China in providing a so-called 'level playing-field' and an opportunity for social mobility ( $\mathrm{Li}, 2009)$. The Chinese imperial system of civil service examinations, originating more than 2,000 years ago during the Han dynasty, carries a powerful residual influence on contemporary education in Confucian-heritage settings, in emphasizing competition and persistence in tackling examinations so as to better one's life chances. On the basis of fieldwork in Japan, South Korea and Taiwan, Zeng (1999) asserts that Confucian-influenced societies believe in meritocratic ideals which hold that examinations bring out positive qualities, such as hard work and determination. Students in Hong Kong do indeed generally work hard, but they seem to do this in order to obtain good examination scores and appease significant family members, more than due to interest in learning for its own sake (Pong \& Chow, 2002).

A student's first taste of competition in schooling in Hong Kong is usually at the age of three, when parents seek a well-established kindergarten which facilitates entry to a good primary school. Students start primary schooling at the age of six. The primary school curriculum is dominated by the three major subjects: Chinese, Mathematics and English. Homework is usually set for these subjects almost every night. Irrespective of their age or social class, students are generally expected to spend a lot of evening time on academic work, such as homework, revision, or studying in the extensive shadow education system of after-hours tutorial schools and private tutoring (Bray \& Kwok, 2003).

A generally accepted image of Chinese parents is presented by Bond (1991): they exert pressure on their children to do well in school; homework is heavily supervised and extends for long periods; strenuous efforts are demanded; private tutors are hired; 
and socializing is largely confined to family gatherings. Chinese parents tend to regard education as the main route for upward social mobility. Indeed, Chinese parents often internalize rigorous expectations for academic performance and attainment, irrespective of their own educational levels (Cheng, 1997). A traditional Confucian view sees academic success or failure as representing honour or disgrace for the family (Li, 2009).

A common arrangement in Hong Kong primary schools is for there to be series of formal internal assessments. There is usually one major test and one examination for each main subject in the two semesters of a school year (Carless, 2011). Each test or examination is often preceded by 'quizzes' or 'mock tests'. These internal school assessments are generally taken very seriously by schools, teachers, students and parents. It has been claimed, with some justification we believe, that there is an almost religious fervour surrounding examinations in Hong Kong (Kennedy et al., 2008).

Formative assessment is part of Hong Kong government policy and it is intended to ameliorate concerns about excessive testing of students. In view of the dominance of summative assessment, it has not been widely implemented in Hong Kong schools (Berry, 2011). The modest literature in relation to assessment in Hong Kong primary schools has mainly focused on teacher implementation of formative assessment (e.g. Carless, 2005; Tang et al., 2010), with little quality research on the student response to assessment.

\section{Methodology}

We seek to address the following research question:

How does a sample of lower primary school students in Hong Kong perceive their experience of assessment?

We elicited student perceptions through two methods: focus group interviews and draw-a-picture technique. In the course of our research, we also interviewed teachers and observed lessons which enabled us to understand better the experience of students in the schools. Consistent with the aim of highlighting student perspectives, we do not report any teacher data or classroom observations in this paper. 


\section{Participants}

The main criterion for our sample schools was not a fully representative sample, but a range of schools across different geographical areas and student ability ranges. We decided to exclude schools of high or low achievers from the sample because we believed that students in elite schools would be more likely to be positively disposed towards assessment and that students in lower achieving schools would be more likely to have negative perceptions. We sought to obtain as far as possible a 'middle-ground' perspective where there were ample prospects for both positive and negative views of assessment. Nine schools expressed interest in participating in our study. They were all aided schools (85\% of Hong Kong primary schools are of this type); in other words financed by government funding but managed by religious orders, charitable organizations or other voluntary bodies. School and government test data, and our own experience of schools, led us to infer that these schools catered for students ranging from slightly above average to slightly below average achievement levels.

We focused our data collection mainly on year 3 students (aged 8 years old) because we believed that their longer experience of school assessment and relatively greater maturity was likely to render them more effective than younger schoolmates at expressing their thoughts. We also, however, wanted to sample some year 1 and 2 students to understand their reactions.

\section{Focus group interviews}

A major means of exploring student perspectives was through focus group interviews which we believed was an appropriate way of enabling young learners to express their perceptions in a non-threatening atmosphere. Although a focus group carries a risk of group conformity (Sim, 1998), our view was that individual interviews might be perceived as somewhat threatening to young learners. Focus group interviews are believed to be an effective way of permitting school age students to talk about their experiences and perceptions, particularly if triangulated with another method (Morgan et al., 2002).

Twenty-one focus groups were carried out in the nine schools. Student informants remained anonymous and were selected by participating teachers nominating a range 
of students from their class involving a balance of high achievers, average achievers and low achievers. The focus groups involved 115 students (56 boys and 59 girls) of which 77 were year 3, 24 were year 2 and 14 were year 1 .

Students were interviewed in their mother tongue by two trained research assistants or the second author. The interview protocol was drafted by one of the research assistants, revised by the first author and then piloted in one school by the other research assistant and revised again. The content of the interviews focused mainly on the following issues: student feelings about testing and assessment; their parents' involvement and reactions towards their performance in tests; and the relationship between testing and learning, including the extent to which tests motivated or supported student learning. Interviews began with initial stimulus questions on these issues and then led to further probing. Small groups of four to six students were interviewed for periods of around twenty to thirty minutes. Interviews were recorded and transcribed, with the bilingual research assistant then translating them into English.

\section{Draw-a-picture technique}

To complement the focus group interviews and in anticipation that some young learners might find it difficult to express fully their experiences of assessment verbally, we also used draw-a-picture technique. Many students are uneasy about answering questions from perceived authority figures, whereas the non-verbal nature of drawings allows a child to express attitudes or emotions that otherwise may not be readily accessed (Barraza, 1999). Draw-a-picture technique has been found to be particularly useful in allowing children to share their feelings and experiences of schooling (Freeman \& Mathison, 2009).

Using guidelines derived from Harris et al., (2009) and Brown and Wang (2011), we asked students to draw a picture based on their strongest feeling or experience of assessment. The students were asked to write a caption below their drawing to explain its meaning. The drawing allied with the student interpretation of it facilitated our understanding of the pictorial data. In total, 76 drawings were collected from 38 year 3 students, 24 year 2 students and 14 year 1 students. 


\section{Data analysis}

Managing subjectivity is an important dimension of qualitative research (e.g. Peshkin, 1988) and a central element in trustworthy data analysis. In line with this perspective, we should acknowledge that our preconceptions about the issue and an aspect of our motivation for the study were concerns that excessive testing in the early years could have a negative impact on student affect. In view of this potential bias, we wish to document our analytic procedures in some detail.

Given the chosen research question, the issues discussed in the interviews and our initial literature reviews, major themes were already provisionally established in our minds. We do not claim that they 'emerged' from the data as they were largely predetermined by the conceptualization of the study. Instead, we saw our task as to code our data carefully, making full use of the presence of two co-authors. We first coded some data together, agreed our procedures and reached some understanding of each others' viewpoints. We then independently coded interview transcripts and drawings/captions.

We noted that there was polarization of student opinions on certain issues along a positive-negative continuum. In the formal analysis, we coded as 'positive', 'negative', 'neutral' or 'mixed', student comments on the two themes which provoked the deepest polarization: affective response to assessment and parental influence. Positive denotes a comment on perceptions of learning, motivational or affective gains, such as: 'Examinations encourage me to study effectively'. Negative denotes a feeling of dislike or potential discomfort, such as: 'I don't like having tests'. It was also quite common for students to combine 'neutral' or 'mixed' perceptions and these were classified as such. An example of a neutral statement is: 'When I think of assessment, I think of my revision strategies'. An example of a mixed caption: 'I am scared of Chinese because I don’t get good grades, but I am happy because I get good grades in English'. Using Kappa’s co-efficient, the inter-rater reliability between the two co-authors for the coding was 0.664 indicating a good (but not excellent) level of agreement. In cases of coding being different, we agreed upon a final code through a process of discussion and negotiation. 


\section{Limitations}

The limitations of our study mainly relate to the sampling strategy which relied on the choice and co-operation of schools and our decision to focus mainly on year 3 students. The small number of participants in years 1 and 2 does not permit us to draw meaningful comparisons across the different age-groups, although this could be an area for further research. In addition, due to time constraints during the busy school schedule, not all year 3 student participants had time to draw pictures. There are also some limitations to how the data can be analyzed. The anonymity of informants does not allow us to gauge the extent to which individual responses come from higher or lower achieving students, so we are not able to gauge the extent to which achievement impacts on students’ perceptions.

\section{Findings}

The findings address three themes: the student affective response to assessment; parental involvement and influence on the students' experience of assessment; and the relationship between testing and student learning. For each of these issues, we present student perspectives from the focus groups and, in view of space limitations, one drawing per theme selected as being illustrative of data on that topic. In order to indicate the balance of the evidence, the overall counts from the coding procedures (described above) are included in the findings for the themes of affective response and parental influence, although not for the third theme which was less polarized. We believe that these numerical data are important so as to indicate the overall trends in the data.

\section{Affective response to assessment}

We asked students about their affective response to assessment and testing. The focus group began with the initial stimulus questions: How do you feel about tests? To what extent do you like or dislike them? From the entire data-set, we coded 253 occurrences of an affective response to assessment. We classified 36\%, $\mathrm{N}=90$ (Focus interviews: 64; Drawings: 26) as indicating a positive affective response to assessment; 47\%, $N=118$ (Focus interviews: 86; Drawings: 32) a negative response to assessment; and 18\%, $\mathrm{N}=45$ (Focus interviews: 27; Drawings: 18) neutral or mixed. In sum, the overall trend is mixed, although more students indicated negative than positive perceptions. Given that little is known about how young learners 
respond to assessment, this may be a significant finding highlighting considerable negative student perceptions.

We found the drawings and their captions particularly useful in identifying student affective response to assessment. Box 1 indicates the most common vocabulary used in the captions, with the number in parentheses indicating frequencies.

Box 1: Word frequencies in drawing captions

\begin{tabular}{|ccc|}
\hline Feel (30) & Happy (26) & Test (22) \\
Nervous (14) & Study (12) & Marks (12) \\
Scores (10) & Exam (10) & Good (9) $\quad$ Low (9) \\
High (8) & Mother (8) & Afraid (7) \\
Scared (5) & Stressed (5) & Unhappy (5) \\
& & \\
\hline
\end{tabular}

Feel (also expressed through the word 'feelings') was the most common item indicating the emotional and perceptual side of assessment. Assessment and its results clearly impact on how students feel about themselves. A positive term 'happy' was the most frequently occurring adjective and it also occurs a number of times in the interview data discussed below. Two other terms 'good' and 'high' also carry a positive connotation. There were a number of terms with negative connotations: 'nervous', 'low', 'afraid', 'scared', 'stressed' and 'unhappy', indicating some of the pressure surrounding examinations.

During the focus group interviews, a number of students commented on affect in relation to testing, for example: 
Tests make us feel better in learning because we can know how much we have learnt. I will feel less stressful after the test.

I am happy to do tests because I want to know the level that I am at.

I feel happy because I usually do well in tests.

I want to get high scores and that will make me happy.

These quotations indicate different aspects of positive affect. The first refers to a perception of satisfaction at knowing one's progress and some reduction in stress on completion of a test. The second also refers to a diagnostic function of assessment in terms of identifying one's level, and perhaps in this case 'happy to do' is a synonym for 'willing to do' rather than an expression of pleasure. The third is an attribution of happiness based on good results in previous tests. The fourth expresses an aspiration of obtaining high scores which will lead to happiness if it occurs. As these quotations indicate, positive affect is mainly connected to doing well in tests or knowing one's progress. Similar to the drawings and captions, the potential of tests to make students 'happy' also occurs.

Below is a selection of quotations from those that were coded as negative:

I would feel anxious before the tests because I don't know if I would be able to do it or if it would be too difficult.

I would study until midnight before the exam. When I feel sleepy during the test, I am afraid that I can’t complete the questions.

I feel scared that my teachers will scold me if I get low marks.

The thing I remember the most is dictation, it makes me unhappy because I always get low marks.

These students are expressing feelings of anxiety, tiredness, fear and unhappiness, indicative of some of the pressure surrounding their experiences of assessment. 
Other students commented on test preparation:

I don't like to have tests because I have to memorize a lot of things for each test. When I have tests, I won't have time to play video games or watch television.

We would revise the homework exercises for the tests because sometimes they will appear in the exam questions. But we feel bored when doing all these.

These comments refer to the challenge of preparing for or taking tests, including memorization of material, associated reduction in leisure time and feelings of boredom. Our inference is that tests act, to some extent, as a disciplinary force because they exert some control on how students arrange their out of school time.

In sum, positive perceptions mainly arise from achieving high scores, feeling relieved at completing a test or identifying one's progress. Negative perceptions were mainly related to aspects of the pressure surrounding testing. Students articulated this pressure in different ways including anxiety, fear and dislike of exam preparation or memorization. Negative perceptions slightly outweigh positive ones, and that these are occurring in the early years of schooling represents for us a cause for concern in that over the longer term they may impact negatively on students' willingness to engage fully and productively with school life.

The phenomenon of mixed feelings of happiness and sadness is illustrated by a drawing which depicts how a student feels before and after an exam (Picture 1 below).

Picture 1 


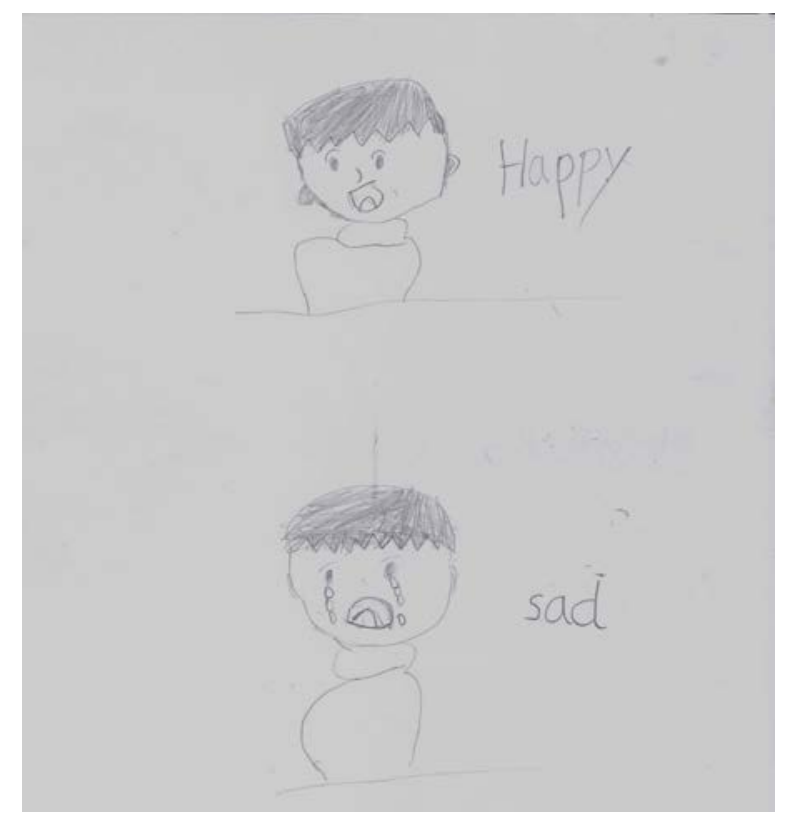

Caption: 'Before the exam, I feel happy and relaxed. After it, I cry and feel confused'.

The picture addresses the theme of student emotions in relation to testing. The student perceived that he usually under-performed in examinations, so he felt sad about his results. Our inference is that his test results impact strongly on how he feels about himself, so he becomes defined by his academic performance.

\section{Parental influence on student perceptions}

We asked informants about how their parents were involved in, or responded to, their experience of assessment. From the entire dataset, we identified 207 (interviews: 198; drawings: 9) times when parents were mentioned. We coded 43\%, $\mathrm{N}=90$ (Focus interviews: 87; Drawings: 3) as positive e.g. parental support or empathy with student difficulties. 51\%, $\mathrm{N}=105$ (interviews: 101; drawings: 4) were coded as negative e.g. pressure or anxiety from parental input. The remaining 6\%, $\mathrm{N}=12$ (10 interviews; 2 drawings) were coded as mixed or neutral. In sum, students perceived the parental influence as mixed, but more negative than positive perceptions were expressed. We believe that this is quite a significant finding as we did not anticipate so many students perceiving parental involvement negatively.

We begin with some quotations from those that were coded as positive parental input: 
If I get a good result, my mum would reward me. Even if I can’t obtain a good result, my mum would not scold me but explain to me how to improve next time.

I wouldn't be scared of exams because even if I failed my mum would comfort me.

Just over half of the comments in relation to parents were coded as negative. Some examples:

My mum always tells me to get higher scores (higher than 90) so I feel a lot of pressure from her.

If my score is below $80 \%$, my parents will scold me or punish me.

I feel worried because if I get low marks, my parents will scold me.

In addition to identifying pressure from parents, these quotes also highlight a student focus on marks and scores, part of the examination apparatus identified in our conceptual framework. The threat of punishment or scolding, part of the disciplinary side of testing, is also evident.

Another student used an analogy to express her perception of parental pressure:

Whenever I revise my textbooks or exercises for the exam, my mum is always sitting next to me. Her presence is like a policewoman more than a tutor who can teach me how to write sentences and pronounce difficult words.

The image of the mother as a policewoman carries connotations of a surveillance aspect to the testing process. It resonates with the orientation of Foucault, whereby the examination process holds the student under observation and acts as a disciplinary force.

Parents were often reported as relating examination success to future opportunities: 
My mother told me, 'You should set a goal in studying for good exam results, as it is the easiest way to get a promising job and have greater earning power in future'.

My parents said, 'By getting a good score, you can go to a nice secondary school and go to university'.

My mother told me, 'If you do not study hard and get full marks, you will become a beggar one day and nobody will give you any money’.

These quotations phrase the outcomes of good examination results in terms of school, university, career and financial opportunities accruing from successful performance; or in terms of the third quotation the disastrous consequences of not just poor test performance but a failure to obtain full marks. The long-term goals expressed by parents may be difficult for lower primary school students to relate to adequately.

The overall trends on this theme suggest that parents have high aspirations for test performance of their offspring and generally exert pressure on students to work hard to prepare themselves for tests. In some senses, parents were holding students accountable for obtaining good grades in tests. Successful performance was often described in relation to enhanced future educational or career opportunities. There were also some reports of parents being supportive or sympathetic if test results were not perceived as good, but these were less frequent than those which put pressure on children to succeed. The data are indicative of the high aspirations of Chinese parents for excellence in examination performance. Whilst high expectations are important and valuable, our data do not allow us to gauge how realistic these aspirations were, or the extent to which they might set up disappointment from ultimately unachievable goals. There may be a need to educate Hong Kong Chinese parents to place more emphasis on balanced development of their offspring, recognizing general well-being and happiness factors, as much as academic achievement (Shek \& Chan, 1999). Alternatively, from a cross-cultural perspective one might speculate whether parents in other cultures might sometimes profitably raise their expectations of the academic achievement of their offspring. 
Picture 2 is chosen to illustrate the theme of parental response to student performance in assessment.

Picture 2
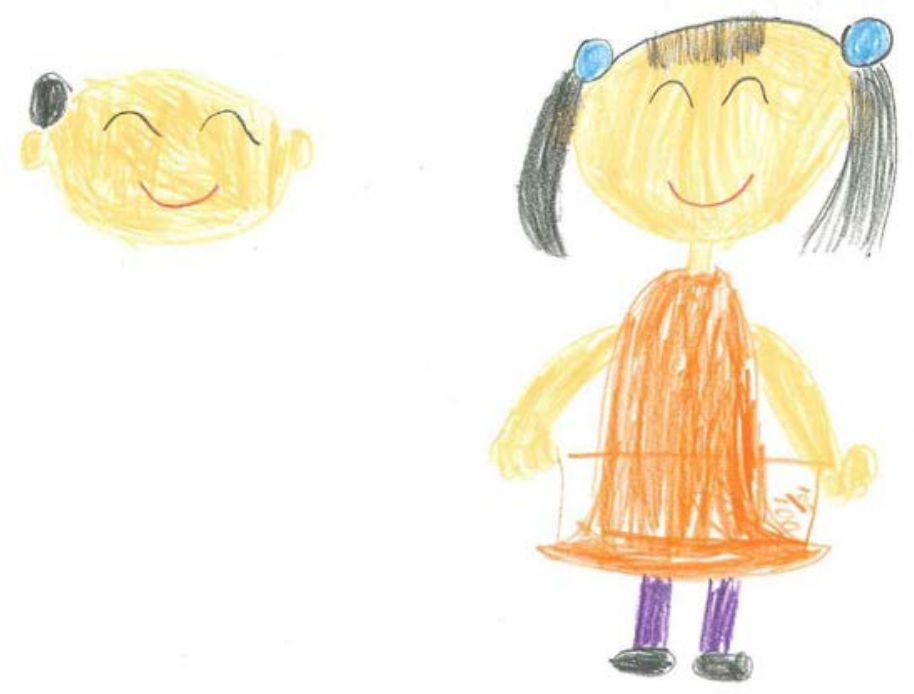

Caption: 'I gave my test paper to my mother. She was very happy because I got 100 . If I got low scores, she will be very angry and will scold me'.

The picture presents a relatively positive image and a score of $100 \%$ is reported as making the parent happy. The caption speaks to the theme of high scores leading to happiness. The caption also appears to carry further possible connotations in that the negative consequences of a 'low score' are reported but it is not clear what constitutes a low score. Might a score in the 90s still be perceived as relatively 'low'? Our interpretation of this student drawing may offer some reinforcement of the aspirations of Hong Kong Chinese parents for very high academic achievement of their offspring.

\section{Testing and learning}

One of the issues raised in the focus group interviews concerned the relationship between testing and learning. The initial stimulus question was phrased as follows: why do you think you need to do tests? Follow-up discussion centred on the extent to which tests helped or motivated students to learn. 
Some examples of student comments:

We might forget about what we have learnt but tests help us to consolidate and review what has been taught previously, as we need to study before the test and retrieve the knowledge during the test.

I think tests and exams help us develop our potential learning abilities. The more tests and exams we have, the better we can achieve.

Tests help us learn because when we get unsatisfactory results in tests, we would find out the areas we should improve on.

We need to have exams because it helps the teacher to find out if we were attentive during lessons.

Without tests, I would play computer games all day. I wouldn’t study.

The first quotation mainly focuses on the role of tests in prompting review of what has previously been taught. The second notes a positive role for tests in the development of student learning and achievement, and adds a further perception of 'the more tests, the better'. The third adds a positive possibility of tests as suggesting areas for further improvement. We interpret the fourth as evoking something of a disciplinary perspective in that a test seems to be a means to encourage attentiveness during lessons. The fifth introduces a further dimension in that the student expresses the view that without the need to prepare for tests, he would not be inclined to study, in other words testing having a coercive impact. The anonymity of the informants does also result in some unanswered questions, notably the relationship between student achievement and their perceptions of testing. For example, is the second student quoted above likely to be a higher achiever than the fifth? In addition, to what extent are students in Hong Kong acculturated from an early age to the examined life and what impact does this have on their response?

Again, the issue of marks or scores was a prominent theme in the interview data. Two student comments: 
If we get a high score from the test, it means that we know more than our classmates.

The test score is important and we want to do better than our classmates. The teacher will always tell us who got a high score and who got a low score. I got $88 \%$ in a test and was quite sad about it because others got more marks.

These quotes provide an indication of competiveness in testing in that the students are comparing their performance with their classmates. The second quotation also indicates the teacher seeming to encourage this form of comparison. Our interpretation is that competition can have some beneficial impacts in terms of its potential to prompt additional student effort and raise standards, but risks exacerbating pressure and may lead to tensions in relationships between students.

A further issue at the interface of testing and learning was test preparation and revision. Some typical student comments:

Teachers would give us lots of revision exercises and they are useful. Usually the test questions are similar to what the teacher has revised with us.

Usually the teachers would give us revision worksheets, help us with some spellings and distribute all the homework worksheets that we have done previously. Then we can take them home and study.

The kind of learning which resulted from test preparation and revision was also mentioned by some informants who made comments we found quite perceptive. For example, a student pointed out that tests primarily promoted memorization of facts and mechanical drilling (e.g. copying of information), and shortly after these tests she would forget what had been tested. Another student commented, however, that dictations and exams were useful in helping her to remember the vocabulary items and sentence patterns that she had learned from the textbook. Beneath the surface of these data is the distinction between mastery and performance (e.g. Dweck, 2000). To what extent do high scores in school tests represent mastery of the material that has been taught? Or, is there a danger that students regurgitate information to obtain a 
good score in a test without being able to apply it effectively or recall it after the test process has been completed?

Picture 3 (below) is chosen to illustrate the sub-theme of revision.

Picture 3

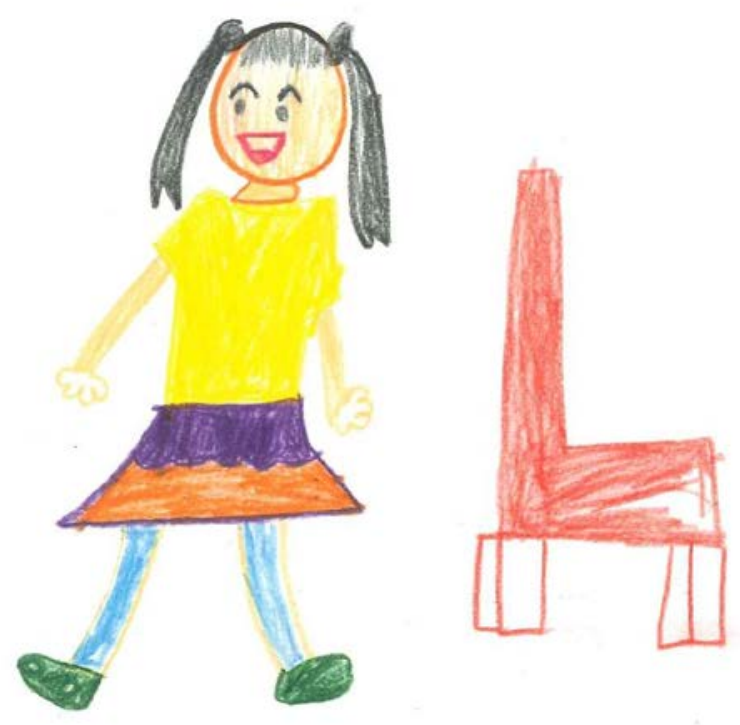

Caption: 'I was doing my revision even when I am walking. I studied very hard for tests. The first thing I remembered when you mentioned assessment was my revision strategies'.

The picture seems relatively positive in that the girl looks happy. The caption indicates a student working hard and busily revising for her tests. A more Foucauldian interpretation might be that the student's continuous revision traps her in the repeated power of the examination.

\section{Discussion}

This exploratory paper sought to uncover student perceptions of assessment in the early years of formal schooling. There was a balance of student viewpoints expressed in relation to their experience of assessment. The main positive messages from the 
data were that assessment could assist students in gauging their progress and identifying their strengths and weaknesses; and when students perceived their test performance was good, it could make them feel happy or trigger praise from significant others, such as teachers and parents. It was also evident that students devoted considerable time to studying, through revision and test preparation as well as regular homework activities. In some senses, this represented some of the power of testing discussed in our conceptual framework. The main negative messages from the data were that a number of students experienced pressure or anxiety in relation to assessment reinforcing similar messages from research in England (e.g. Hall et al., 2004). It seemed that in comparison with research in Anglophone contexts, our data highlighted more prominently the active involvement of parents in exhorting their offspring to study hard. This was sometimes related to a disciplinary aspect of the testing process in relation to threats of punishment or scolding.

The paper has discussed empirical data which speaks to the issues raised in our conceptual framework. Whether students were largely positive or negative about their assessment experience, they were defined by it in terms of their own self-worth or as judged by other family members. Students (and possibly parents, too) were to a large extent controlled by tests in terms of how they spent their time and how they viewed education. The test score was all important and students were fixed and judged by numbers. As Bourdieu (1991) implies, a small difference in the score could impact on how a student was perceived. The paper has thereby provided some corroboration of how students are moulded by assessment; and that how they feel about schooling and how their families perceive them are guided by their performance in tests. Our perception was that this performance and the score associated with it were sometimes prioritized over the extent to which students were actually involved in meaningful learning.

Previous research (Moni et al., 2002; Wheelock et al., 2000) has suggested that students' affective response to assessment becomes more negative as they progress into and through secondary schooling (and the stakes become higher). A pertinent finding from the balance of evidence in the current study was that lower primary school students already had quite a lot of negative perceptions and experiences of assessment. The early years' reporting of test pressure marks a difference between our 
research and literature reviewed earlier, for example, studies at the end of primary schooling (Hall et al., 2004; Reay \& Wiliam, 1999). A niche for our work is in this reporting of student perceptions of test pressure in the lower primary school; few studies have documented this phenomenon with this age group, although in their analysis of self-esteem Davies and Brember (1998) discussed analogous issues.

When Black and Wiliam (2005) claimed that students in England were overtaking students from the US in being the most tested in the world, they seemed to overlook the East Asian student experience where a heavy diet of testing is a reality from the age of six onwards. In contemporary schooling, students (and teachers) seem to be controlled by assessment. The Hong Kong case is a relatively extreme one, but the issues are universal. To present a detailed argument to counter this dominance of testing would require a paper in itself. Suffice it to say that formative assessment might be a significant part of a proposed solution, despite the risk that formative approaches often become crowded out by the power of summative assessment (Stobart, 2008). Prospects lie in evidence (e.g. Meisels et al., 2003; Wiliam et al., 2004) that well-implemented formative assessment leads to enhanced performance in summative assessment. If this message could become more widely accepted, then developing productive synergies between formative and summative assessment might become a feasible means of reconciling tensions between the two.

\section{Conclusion}

The centrality of testing in the lives of students has been evident over the last twenty years. This paper has reinforced such messages, and has elaborated on two less widely discussed elements. First, it has discussed perceptions of the examined life experienced by lower primary school learners. These included satisfaction in obtaining good results, and pressure expressed by more than half of the students in our sample. Second, it documents Hong Kong students’ perspectives on assessment, notable because there are few detailed analyses of this topic outside the main Anglophone settings. We have sought to provide a balanced portrayal of the issues, but feel justified in expressing our concerns for students who face test anxiety and stress from the age of six onwards. Results from international tests of achievement are a testament to the strong academic performance of Chinese students, many of them also go on to perform well at elite universities worldwide. Is it more because of the 
testing regimes they experience from a young age or in spite of them? When does a certain amount of pressure act as a positive impetus to study, and when does it have negative short-term or longer-term impacts? To what extent, and when, does competition help to raise standards or is it more likely to lead to anxiety and unproductive rivalries between students? Our data, of course, do not enable us to answer these questions, but we feel justified in airing them and signaling them as potential areas for further research.

\section{Acknowledgement}

This research was supported by a General Research Fund grant from the Research Grants Council of Hong Kong: HKU740609H.

\section{References}

Barraza, L. 1999. Children's drawings about the environment. Environmental Educational Research 5, no. 1: 49-66.

Berry, R. 2011. Assessment trends in Hong Kong: Seeking to establish formative assessment in an examination culture. Assessment in Education 18, no. 2: 199211.

Biggs, J. ed. 1996. Testing: To educate or select? Hong Kong: Hong Kong Educational Publishing.

Black, P. 1998. Testing: Friend or foe? London: Falmer.

Black, P., and D. Wiliam. 2005. Lessons from around the world: How policies, politics and cultures constrain and afford assessment practices. The Curriculum Journal 16, no. 2: 249-261.

Bond, M. 1991. Beyond the Chinese face: Insights from psychology. Hong Kong: Oxford University Press.

Bourdieu, P. 1991. Language and symbolic power. Cambridge, MA: Harvard University Press.

Bourdieu, P., and J.C. Passeron. 1990. Reproduction in education, society and culture. London: Sage.

Bray, M., and P. Kwok. 2003. Demand for private supplementary tutoring: conceptual considerations and socio-economic patterns in Hong Kong. Economics of Education Review 22, no. 6: 611-620. 
Brown, G., and Z. Wang. 2011. Illustrating assessment: How Hong Kong university students conceive of assessment's purposes. Studies in Higher Education 39, no. 2. DOI:10.1080/03075079.2011.616955

Carless, D. 2005. Prospects for the implementation of assessment for learning. Assessment in Education 12, no. 1: 39-54.

Carless, D. 2011. From testing to productive student learning: Implementing formative assessment in Confucian-heritage settings. New York: Routledge.

Cheng, K. 1997. The education system. In Schooling in Hong Kong: Organisation, teaching and social context, eds. G. Postiglione, and W. Lee, 25-42. Hong Kong: Hong Kong University Press.

Davies, J., and I. Brember. 1998. National curriculum testing and self-esteem in year 2. The first five years: A cross-sectional study. Educational Psychology, 18: 365375.

Dweck, C. 2002. Messages that motivate. In Improving academic achievement: Impact of psychological factors on education, ed. J. Aronson, 38-61. San Diego: Elsevier.

Foucault, M. 1979. Discipline and punish: The birth of the prison. New York: Vintage Books.

Freeman, M., and S. Mathison. 2009. Researching children's experiences. New York: The Guilford Press.

Gipps, C. 1999. Socio-cultural aspects of assessment. Review of research in Education 24, no. 1: 355-392.

Hall, K., J. Collins, S. Benjamin, M. Nind, and K. Sheehy. 2004. SATurated models of pupildom: Assessment and inclusion/exclusion. British Educational Research Journal 30, no. 6: 801-817.

Hanson, F.A. 1993. Testing testing: Social consequences of the examined life. Berkeley, CA: University of California Press.

Harlen, W. 2006. The role of assessment in developing motivation for learning. In Assessment and learning, ed. J. Gardner, 61-80. London: Sage.

Harlen, W., and R. Deakin Crick. 2003. Testing and motivation for learning. Assessment in Education 10, no. 2: 169-207.

Harris, L., G. Brown, and J. Harnett. 2009. “Drawing” out student conceptions: Using pupils' pictures to examine their conceptions of assessment. In Student 
perspectives on assessment, eds. D. McInerney, G. Brown, and G. Liem, 53-84. Charlotte, NC: Information Age Publishing.

House, J. 2003. Self-beliefs and reading achievement of elementary-school students in Hong Kong and the United States: Results from the PIRLS 2001. Child study journal 33, no. 4: $195-212$.

Kennedy, K., J. Chan, P. Fok, and W. Yu. 2008. Forms of assessment and their potential for enhancing learning: conceptual and cultural issues. Educational Research for Policy and Practice 7, no. 3: 197-207.

Li, J. 2009. Learning to self-perfect: Chinese beliefs about learning. In Revisiting the Chinese learner: Changing contexts, changing education, eds. C. Chan and N. Rao, 35-69. Hong Kong: Springer and Comparative Education Research Centre.

Meisels, S., S. Atkinds-Burnett, Y. Xue, J. Nicholson, D. Bickel and S. Son. 2003. Creating a system of accounting ability: The impact of instructional assessment on elementary children's achievement scores. Educational Policy Analysis Archives, 11(9). Accessed August 2, 2010 from http://epaa.asu.edu/epaa/v11n9

Moni, K., C. Van Kraayenoord, and C. Baker. 2002. Students' perceptions of literacy assessment. Assessment in Education 9, no. 3: 319-342.

Morgan, M., S. Gibbs, K. Maxwell and N. Britten, N. 2002. Hearing children's voices: Methodological issues in conducting focus groups with children aged 7-11 years. Qualitative Research 2, no. 1: 5-20.

Peshkin, A. 1988. Virtuous subjectivity: in the participant-observer's I's. In The self in social inquiry, eds. D. Berg, and K. Smith, 267-282. Newbury Park, CA: Sage.

Pollard, A., and P. Triggs. 2000. What pupils say: Changing policy and practice in primary education. New York: Continuum.

Pong, W., and J. Chow. 2002. On the pedagogy of examinations in Hong Kong. Teaching and Teacher Education 18, no. 2: 139-149.

Reay, D., and D. Wiliam. 1999. 'I'll be a nothing': Structure, agency and the construction of identity through assessment. British Educational Research Journal 25, no. 3: 343-354.

Shek, D.T.L., and L.K. Chan. 1999. Hong Kong Chinese parents' perceptions of the ideal child. The Journal of Psychology 133, no.3: 291 - 302.

Shen, C., and H. Tam. 2008. The paradoxical relationship between student achievement and self-perception: a cross-national analysis based on three waves of TIMSS data. Educational Research and Evaluation 14, no. 1: 87-100. 
Shohamy, E. 1998. Critical language testing and beyond. Studies in Educational Evaluation 24, no. 4: 331-345.

Shohamy, E. 2001. The power of tests: A critical perspective on the uses of language tests. Harlow: Longman.

Sim J. 1998. Collecting and analysing qualitative data: Issues raised by the focus group. Journal of Advanced Nursing 28, no. 2: 345-352.

Stobart, G. 2008. Testing times: The uses and abuses of assessment. New York: Routledge.

Tang, S., P. Leung, A. Chow, and P. Wong. 2010. A case study of teacher learning in an assessment for learning project in Hong Kong. Professional Development in Education 36, no. 4: 621-636.

Wheelock, A., D. Bebell and W. Haney. 2000. What can student drawings tell us about high-stakes testing in Massachusetts? Teachers College Record, http://www.tcrecord.org ID Number: 10634, Accessed $4^{\text {th }}$ October 2011.

Wiliam, D., C. Lee, C. Harrison and P. Black. 2004. Teachers developing assessment for learning: Impact on student achievement. Assessment in Education 11, no. 1: 49-65.

Zeng, K. 1999. Dragon gate: Competitive examinations and their consequences. London: Cassell. 